\title{
Inhibition of Neutral Amino Acid Transport Across the Human Blood-Brain Barrier by Phenylalanine
}

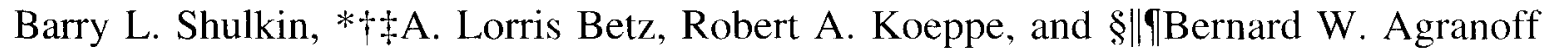 \\ Departments of Internal Medicine (Division of Nuclear Medicine), *Pediatrics, † Surgery (Neurosurgery), \\ $\ddagger$ Neurology, §Psychiatry, and |Biological Chemistry and $\mid$ Mental Health Research Institute, \\ University of Michigan Medical School, Ann Arbor, Michigan, U.S.A.
}

\begin{abstract}
The delivery of large neutral amino acids (LNAAs) to brain across the blood-brain barrier (BBB) is mediated by the L-type neutral amino acid transporter present in the membranes of the brain capillary endothelial cell. In experimental animals, the L-system transporter is saturated under normal conditions, and therefore an elevation in the plasma concentration of one LNAA will reduce brain uptake of others. In this study, we used positron emission tomography (PET) to determine the effect of elevated plasma phenylalanine concentrations on the uptake of an artificial neutral amino acid, $\left[{ }^{11} \mathrm{C}\right]-$ aminocyclohexanecarboxylate $\left(\left[{ }^{11} \mathrm{C}\right] \mathrm{ACHC}\right)$, in human brain. PET scans were performed on six normal male subjects after an overnight fast and again $60 \mathrm{~min}$ after oral administration of $100 \mathrm{mg} / \mathrm{kg}$ of phenylalanine. The plasma phenylalanine concentration increased by an average of 11-fold between the first and second scans. This increase produced a reduction in $\left[{ }^{11} \mathrm{C}\right] \mathrm{ACHC}$ uptake in all brain regions but not in scalp. The mean $\pm S D$ influx rate constant for whole brain decreased after phenylalanine ingestion from $0.036 \pm 0.002$ to $0.019 \pm 0.004 \mathrm{ml} / \mathrm{g} /$ $\mathrm{min}$. Kinetic analysis of the effect of plasma phenylalanine concentration on the rate of $\left[{ }^{11} \mathrm{C}\right] \mathrm{ACHC}$ uptake is compatible with a model of competitive inhibition so that large increases in the concentration of one LNAA in plasma will reduce the brain uptake of other LNAAs across the human BBB. Key Words: Aminocyclohexanecarboxylate-Positron emission tomography-L-system transporter-Essential amino acids.
\end{abstract}

J. Neurochem. 64, 1252-1257 (1995).

Because the blood-brain barrier ( BBB) isolates the brain from the blood, the delivery of many essential metabolic substrates to brain is dependent on carriermediated transport systems that are present in the membranes of the brain capillary endothelial cell (Pardridge, 1983; Goldstein and Betz, 1986). Large neutral amino acids (LNAAs) belong to this group of essential substrates because they cannot be produced by brain, but they are required for the synthesis of proteins and certain neurotransmitters. Indeed, it has been suggested that the availability of amino acid precursors from the blood may limit the synthesis of serotonin, histamine, phenylethylamine, tyramine, norepinephrine, kynurenic acid, and quinolinic acid (reviewed elsewhere by Pardridge, 1986; Smith, 1991).

LNAAs enter brain via an L-type neutral amino acid transporter that is present in the BBB (Pardridge, 1977, 1983; Smith et al., 1987; Smith, 1991). This transporter has affinity for many naturally occurring amino acids, which compete with each other for entry into brain. Based on the results of kinetic analyses of LNAA transport in animals, it has been proposed that the L-system transporter of the BBB is nearly saturated under normal conditions, and therefore an elevation in the plasma concentration of one LNAA will reduce brain uptake of others (Pardridge, 1986; Smith et al., 1987; Smith, 1991). Because phenylalanine has the highest affinity for the transporter (Smith et al., 1987; Hargreaves and Pardridge, 1988), changes in its concentration have the greatest impact on the uptake of other LNAAs. If this relationship is also true in humans, it may help to explain the brain dysfunction that occurs in phenylketonuria (Kaufman, 1977; Pardridge, 1986) and the inconsistent response seen in some patients with Parkinson's disease who are treated with L-DOPA (which is also transported by the L-system) at various times after meals (Daniel et al., 1976; Carter et al., 1989). It is also compatible with the proposal that the ingestion of large amounts of the low-calorie sweetener aspartame (L-aspartyl-L-phenylalanine methyl ester) might increase plasma phenylalanine concentrations enough to affect brain amino acid metabolism (Pardridge, 1986). However, in a previous study of LNAA transport into the human brain, we found that a 2.5 -fold increase in plasma phenylalanine concentration resulting from the ingestion of an ex-

Received March 10, 1994; revised manuscript received August 4 1994; accepted August 26, 1994.

Address correspondence and reprint requests to Dr. A. L. Bet $z$ at 5605 Kresge Research I, University of Michigan Medical School, Ann Arbor, Ml 48109-0532, U.S.A.

Abbreviations used: $\mathrm{ACHC}$, aminocyclohexanecarboxylate; $\mathrm{BBB}$, blood-brain barrier; DV, distribution volume; LNAA, large neutral amino acid; PET, positron emission tomography 
cessive amount of aspartame reduced the uptake of a synthetic LNAA, $\left[{ }^{11} \mathrm{C}\right]$ aminocyclohexanecarboxylate ( $\left.{ }^{11} \mathrm{C}\right] \mathrm{ACHC}$ ), by only $11.5 \%$ (Koeppe et al., 1991). Therefore, in the present study we determined the effect of a much larger change in plasma phenylalanine concentration on LNAA transport into human brain by administering phenylalanine itself rather than aspartame.

\section{MATERIALS AND METHODS}

The preparation and use of $\left[{ }^{11} \mathrm{C}\right] \mathrm{ACHC}$ for positron emission tomography (PET) studies have been described previously (Koeppe et al., 1990). In brief, the radiotracer was synthesized via a Bucherer-Strecker reaction of cyclohexanone with $\left[{ }^{11} \mathrm{C}\right] \mathrm{HCN}$ in the presence of ammonium carbonate and ammonium chloride according to the method of Hayes et al. (1978). The yield after purification by ion exchange chromatography was $\sim 100 \mathrm{mCi}$ of $\left[{ }^{11} \mathrm{C}\right] \mathrm{ACHC}$. This was diluted with normal saline and sterilized by filtration. The injection volume of $10 \mathrm{ml}$ contained $30 \mathrm{mCi}$ of I $\left.^{11} \mathrm{C}\right] \mathrm{ACHC}$ with an ACHC mass of $<5 \mathrm{mg}$. Radiochemical purity as judged by radio-HPLC was $>98 \%$. The absence of unreacted cyanide was confirmed by colorimetric assay before administration.

The research protocol was approved by institutional review boards (Committee for the Use of Human Subjects in Research and the Radioactive Drug Research Committee), and informed consent was obtained from each subject before their participation in the study. Six healthy male volunteers 21-43 years old were recruited from the local community by advertisement. Each underwent a brief history and physical and neurological examination and was judged to be in good health and without neurologic abnormalities.

After an overnight fast, subjects reported to the PET laboratory, and a catheter was placed in the radial artery. The subjects' heads were aligned parallel to the canthomeatal line and restrained by a band across the forehead attached to a headholder. Each subject then received $30 \mathrm{mCi}$ of $\left[{ }^{11} \mathrm{C}\right]$ ACHC i.v. over $30 \mathrm{~s}$. PET scanning was performed using a Siemens model CTI 931/08-12 whole-body scanner. This device generates 15 cross-sectional images (eight direct and seven cross planes) and has an intrinsic resolution using the nonwobbled mode of $5.8 \mathrm{~mm}$ full width at half-maximum and a slice thickness of $6.5-8.0 \mathrm{~mm}$. Baseline scans were obtained as a dynamic sequence of 12 frames over a 60 -min period, i.e., $5 \times 1 \mathrm{~min}, 2 \times 2.5 \mathrm{~min}, 2 \times 5 \mathrm{~min}, 2 \times 10$ $\mathrm{min}$, and $1 \times 20 \mathrm{~min}$, after which the subjects were removed from the scanner and given $100 \mathrm{mg} / \mathrm{kg}$ of L-phenylalanine (General Nutrition Corp., Pittsburgh, PA, U.S.A.) orally. The dose of phenylalanine was divided so that $50 \mathrm{mg} / \mathrm{kg}$ was given in capsules and $50 \mathrm{mg} / \mathrm{kg}$ was given as a slurry in $\sim 300 \mathrm{ml}$ of tap water. This combination was found to give an optimal plasma phenylalanine curve. A pilot study of two subjects indicated that the rise in plasma phenylalanine level was too protracted if only phenylalanine capsules were used. At 60 min following administration of phenylalanine, the subjects received another $30 \mathrm{mCi}$ dose of $\left[{ }^{11} \mathrm{C}\right]$ $\mathrm{ACHC}$, and a second PET scan was acquired with the same protocol.

During the PET scans, arterial blood was sampled for determination of radioactivity and plasma amino acid concentrations. Samples for radioactivity were obtained as rapidly as possible during the first 2 min following $\left[{ }^{11} \mathrm{C}\right] \mathrm{ACHC}$ injection and then at progressively longer intervals, increasing to $10 \mathrm{~min}$ by the end of the scan. Plasma was separated by centrifugation and counted in a $\mathrm{NaI}$ scintillation well counter. Blood samples for amino acid analysis were withdrawn at -60 (immediately before the first scan), 0 (time of phenylalanine ingestion), 10, 20, 30, 45, 60 (time of second scan ), 90, and $120 \mathrm{~min}$, added to a small volume of EDTA, and placed on ice. Blood cells were removed by centrifugation, the plasma was deproteinized by centrifugation through an ultrafiltration membrane, and the filtrate was removed and stored at $-70^{\circ} \mathrm{C}$. The plasma concentrations of phenylalanine, tyrosine, methionine, leucine, isoleucine, and valine were subsequently determined by HPLC (Hariharan et al., 1993).

A two-compartment, two-rate parameter tracer kinetic model was applied to the dynamic PET data (Koeppe et al., 1990). This model provides estimates of the uptake rate constant, $K_{1}(\mathrm{ml} / \mathrm{g} / \mathrm{min})$, describing the transport from plasma across the $\mathrm{BBB}$, and the clearance rate constant, $k_{2}$ $(1 / \mathrm{min})$, describing the rate of transport from brain back to blood. The ratio of $K_{1} / k_{2}$ is a measure of the tracer distribution volume, DV $(\mathrm{ml} / \mathrm{g})$. Functional images of the uptake and clearance rate constants and DV were obtained from a rapid pixel-by-pixel estimation procedure using weighted integrals (Alpert et al., 1984). The first $3 \mathrm{~min}$ of data was excluded from the analysis to minimize the effects of bloodborne radioactivity (Koeppe et al., 1990). Mean $K_{1}$ and $k_{2}$ values were determined from seven predetermined brain regions as well as from whole brain and scalp.

The rate of transport $(v)$ of an amino acid in the presence of multiple competing amino acids can be described by the following equation, where $C$ is the plasma concentration of the amino acid, $i$ is the plasma concentration of each competing amino acid, $V_{\max }$ is the maximal rate of transport, $K_{\mathrm{m}}$ is a measure of the affinity of the amino acid, $K_{\mathrm{d}}$ is its rate of simple diffusion from blood to brain, and $K_{\mathrm{i}}$ is the affinity of each of the competing amino acids (Smith et al., 1985):

$$
\nu=\frac{V_{\operatorname{mix}} C}{C+K_{\mathrm{m}}\left(1+\sum \frac{i}{K_{\mathrm{i}}}\right)}+K_{\mathrm{d}} C
$$

When $K_{1}$ is independent of the rate of blood flow (Fenstermacher et al., 1981), $\nu=K_{1} \cdot C$ and therefore

$$
K_{1}=\frac{V_{\max }}{C+K_{\mathrm{m}}\left(1+\sum \frac{i}{K_{\mathrm{i}}}\right)}+K_{\mathrm{d}}
$$

In this study, $\mathrm{ACHC}$ is used at a tracer concentration. Therefore $C=0$, and this equation can be rewritten as

$$
K_{1}^{\mathrm{ACHC}}=\frac{V_{\mathrm{max}}^{\mathrm{ACHC}}}{K_{\mathrm{m}}^{\mathrm{ACHC}}\left(1+\sum \frac{i}{K_{\mathrm{i}}}\right)}+K_{\mathrm{d}}^{\mathrm{ACHC}}
$$

The effect of varying the concentration of a single amino acid such as phenylalanine (Phe) is given by

$$
K_{\uparrow}^{\mathrm{ACHC}}=\frac{V_{\mathrm{max}}^{\mathrm{ACHC}}}{K_{\mathrm{m}}^{\mathrm{ACHC}}} \cdot \frac{K_{\mathrm{i}}^{\text {Phe }}}{\text { Phe }+K_{\mathrm{i}}^{\text {Phe }}\left(1+\sum \frac{i}{K_{\mathrm{i}}}\right)}+K_{\mathrm{d}}^{\mathrm{ACHC}}
$$

$K_{1}^{A C H C}$ and the concentrations of phenylalanine and competing amino acids $(i)$ are determined in our studies. Thus, if 
the $K_{\text {}}$ values for the competing amino acids are known and $K_{!}^{\mathrm{ACHC}}$ is measured over a range of phenylalanine concentrations, then we can estimate $K_{\mathrm{i}}^{\text {Phe }}, K_{\mathrm{d}}^{\mathrm{ACHC}}$, and $\left(V_{\mathrm{max}} / K_{\mathrm{m}}\right)^{\mathrm{ACHC}}$ from Eq. 4 using standard nonlinear least-squares fitting procedures.

To increase the number of data points and to include subjects with an intermediate rise in plasma phenylalanine, we combined our previously reported results from subjects receiving aspartame (Koeppe et al., 1991) with those of the present study. Because the previous study was performed with a different PET scanner, the $K_{\text {I }}$ values obtained in that study were normalized to the values obtained with the scanner used in the present study by using the ratio of mean baseline $K_{1}$ values for the new and old scanners $(0.036 /$ 0.031 ).

Solution of Eq. 4 requires knowledge of the concentration (i) and inhibition constants $\left(K_{\mathrm{i}}\right)$ for the competing amino acids. In most cases of competitive inhibition, the $K_{\mathrm{i}}$ of an inhibitor is the same as its affinity for the transporter, i.e., its $K_{\mathrm{m}}$, as has been shown for the BBB LNAA transporter (Pardridge, 1977). As noted above, the concentrations of tyrosine, methionine, leucine, isoleucine, and valine were available, but neither $K_{\mathrm{i}}$ nor $K_{\mathrm{m}}$ values at the human BBB in vivo are known. We therefore performed the analysis using the values for $K_{\mathrm{m}}$ reported in the rat (Smith et al., 1987 ) and those reported for isolated human brain capillaries (Hargreaves and Pardridge, 1988).

Results for $K_{1}, k_{2}$, DV, and levels of plasma amino acids are reported as mean \pm SD values. Statistical comparisons of values obtained before and after phenylalanine ingestion were made using a two-tailed Student's $t$ test for paired samples.

\section{RESULTS}

Fasting phenylalanine levels were $46 \pm 8 \mu \mathrm{M}$, and levels rose to $538 \pm 240 \mu M$ at $30 \mathrm{~min}$ following ingestion of $100 \mathrm{mg} / \mathrm{kg}$ of phenylalanine (Fig. 1A). The mean values were stable through $90 \mathrm{~min}$ and then declined. The concentration of tyrosine also rose after phenylalanine administration (Fig. 1B), reflecting the peripheral conversion of phenylalanine to tyrosine. At the time of the second PET scan, tyrosine content was increased approximately twofold $(p<0.01)$. The concentrations of the other LNAAs quantified were not significantly different at the time of the second scan.

Functional images of $K_{1}$ and DV for a typical subject before and after phenylalanine administration are shown in Fig. 2, and mean \pm SD values for selected brain regions, whole brain, and scalp are shown in Table 1 . Whole-brain values (mean $\pm \mathrm{SD}$ ) for $K_{1}$ decreased from $0.036 \pm 0.002$ to $0.019 \pm 0.004 \mathrm{ml} / \mathrm{g} /$ $\min (p<0.0001)$ after phenylalanine ingestion. All brain regions examined showed a similar reduction; however, $K_{1}$ in the scalp was not significantly changed. In contrast, changes in $k_{2}$, the rate constant for $\left[{ }^{11} \mathrm{C}\right]$ $\mathrm{ACHC}$ efflux from brain, were smaller. This might indicate that, over the interval of this study, the concentration of phenylalanine in the brain's interstitial fluid did not increase as substantially as it did in the blood.

The relationship between whole-brain $K_{1}$ and plasma phenylalanine concentrations for the six subjects of
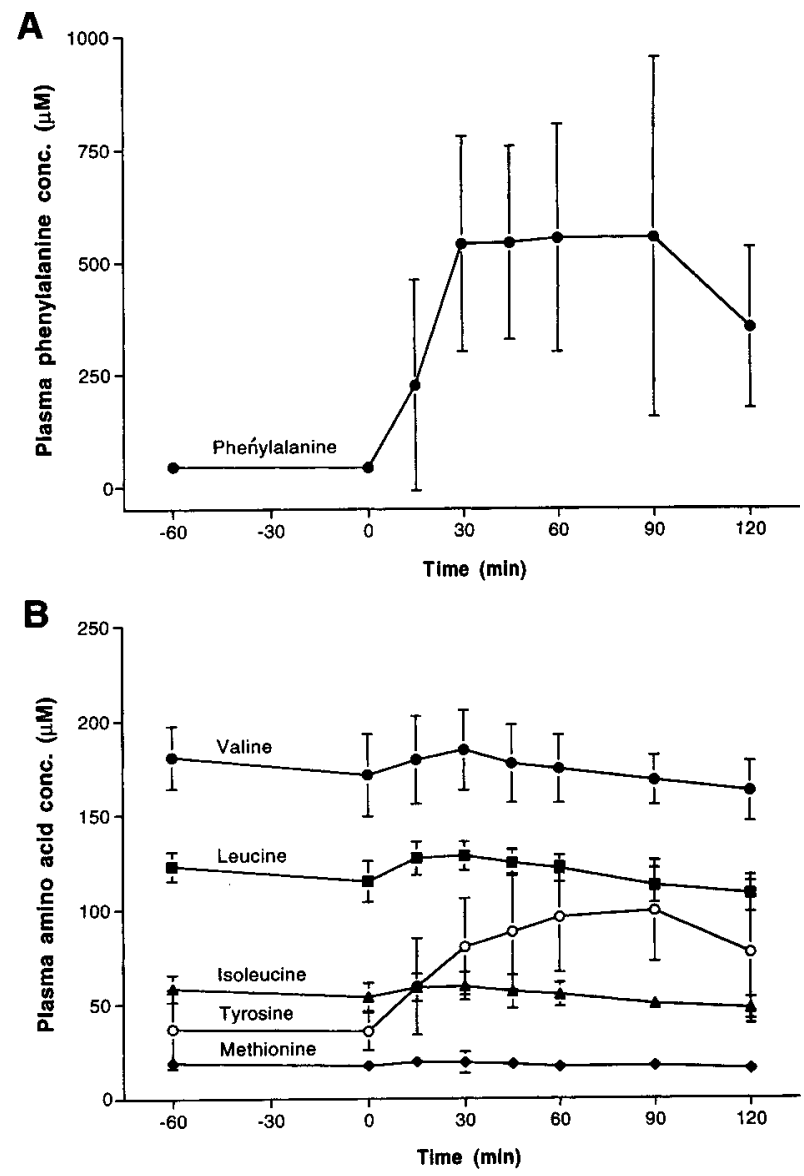

FIG. 1. Change in plasma $L N A A$ concentrations after oral administration of $100 \mathrm{mg} / \mathrm{kg}$ of phenylalanine. Blood samples were obtained $1 \mathrm{~h}$ before ( $-60 \mathrm{~min}$ ) and at various times after ingestion of phenylalanine at zero-time. Data for phenylalanine $(\mathbf{A})$ and other LNAAs $(\mathbf{B})$ are mean \pm SD (bars) values of determinations from six subjects.

this study and another eight subjects that were given aspartame in a previous study is shown in Fig. 3. The concentration-dependent reduction in $K_{1}$ is consistent with competitive inhibition of $\left[{ }^{11} \mathrm{C}\right] \mathrm{ACHC}$ uptake by phenylalanine. To determine the kinetic constants for transport, we fitted these data to Eq. 4 using the $K_{\mathrm{m}}$ values for amino acids other than phenylalanine that have been reported in rats (Smith et al., 1987) and in microvessels isolated from human brain (Hargreaves and Pardridge, 1988). In general, the $K_{\mathrm{m}}$ values are eight- to 40-fold lower in the latter compared with the former study. As shown in Table 2, both analyses give similar values for the rate of $\mathrm{ACHC}$ diffusion into brain, values that are slightly greater than the $0.0060-$ $0.0096 \mathrm{ml} / \mathrm{g} / \mathrm{min}$ reported for $\mathrm{ACHC}$ diffusion into rat brain (Aoyagi et al., 1988). In addition, the $K_{\mathrm{i}}$ values calculated for phenylalanine are similar to the experimentally determined values of $11 \mu M$ in the rat (Momma et al., 1987; Smith et al., 1987) and $0.3 \mu M$ in isolated human brain microvessels (Hargreaves and Pardridge, 1988). 
FIG. 2. Representative [ $\left.{ }^{11} \mathrm{C}\right] \mathrm{ACHC}$ PET scans for one subject before and 60 min after oral administration of phenylalanine. Images at four different levels show the marked reduction in the influx rate constant $\left(K_{1}\right)$ for $\mathrm{ACHC}$ in most brain regions but not in the scalp.

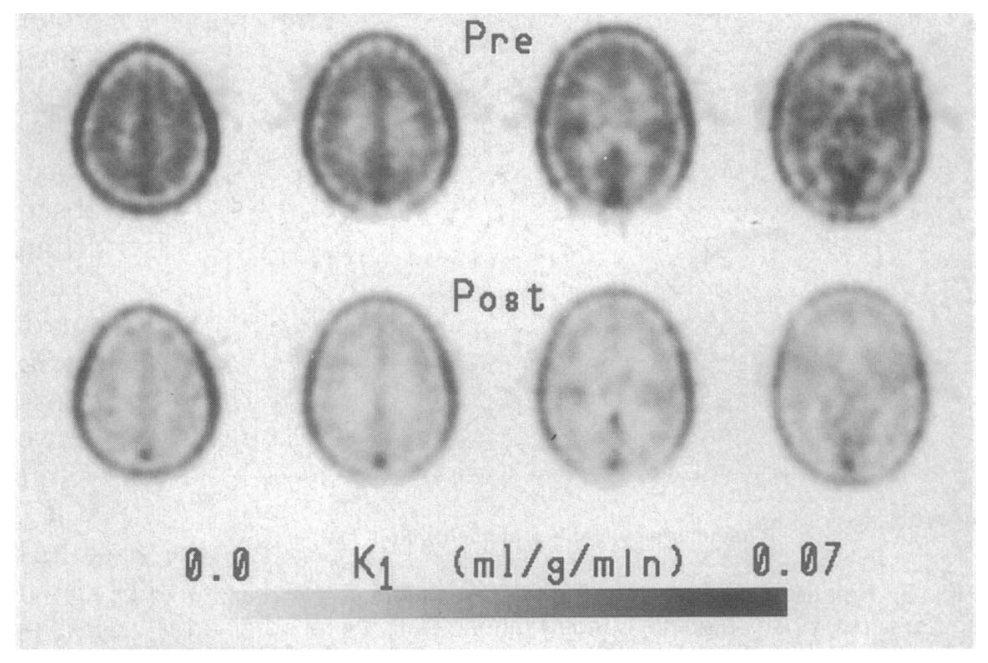

tions for those amino acids that have the highest affinity for the transporter, such as phenylalanine.

It is not surprising that there are few prior studies of LNAA transport across the BBB of humans and that there are no kinetic studies of competitive inhibition in vivo. An early study by Oldendorf et al. (1971) indicated that the brain uptake of $\left.l^{75} \mathrm{Se}\right]$ selenomethionine is reduced in phenylketonurics. Leenders et al. (1986) demonstrated reduced brain uptake of 6${ }^{18} \mathrm{~F} \mid$ fluoro-I.-DOPA measured by PET in a patient who received an intravenous infusion of eight LNAAs. Bergström et al. ( 1987 ) used PET to demonstrate that the accumulation rate of $\mathrm{L}-\mathrm{I}^{11} \mathrm{C}$ / methionine was decreased by $\sim 35 \%$ in normal brain after intravenous infusion of an amino acid mixture containing leucine, isoleucine, and valine. Using both a dual-probe positron detection system and PET, O'Tuama et al. ( 1988 ) measured the influx rate constant for $\mathrm{L}-\left[{ }^{11} \mathrm{C}\right]-$ methionine in normal subjects before and after the oral consumption of $100 \mathrm{mg} / \mathrm{kg}$ of phenylalanine. Influx decreased by an average of $33 \%$ following oral phenyl-

TABLE 1. Regional BBB transport rate constants and tissue DV values for ACHC pre-and postadministration of $100 \mathrm{mg} / \mathrm{kg}$ of phenylalanine

\begin{tabular}{|c|c|c|c|c|c|c|}
\hline \multirow[b]{2}{*}{ Region } & \multicolumn{2}{|c|}{$K_{1}(\mathrm{ml} / \mathrm{g} / \mathrm{min})$} & \multicolumn{2}{|c|}{$k_{2}(1 / \min )$} & \multicolumn{2}{|c|}{ DV $(m 1 / g)$} \\
\hline & Baseline & Post-Phe & Baseline & Post-Phe & Bascline & Post-Phe \\
\hline Scalp & $0.032 \pm 0.004$ & $0.028 \pm 0.006$ & $0.054 \pm 0.004$ & $0.053 \pm 0.011$ & $0.60 \pm 0.06$ & $0.55 \pm 0.06^{\prime \prime}$ \\
\hline Whole brain & $0.036 \pm 0.002$ & $0.019+0.004^{\prime \prime}$ & $0.041 \pm 0.004$ & $0.034 \pm 0.004$ & $0.88 \pm 0.06$ & $0.55 \pm 0.09$ \\
\hline Frontal cortex & $0.040 \pm 0.003$ & $0.019 \pm 0.004^{h}$ & $0.043 \pm 0.004$ & $0.035 \pm 0.006^{\circ}$ & $0.92 \pm 0.07$ & $0.56+0.12$ \\
\hline Parietal cortex & $0.035 \pm 0.002$ & $0.016+0.004^{\prime \prime}$ & $0.044 \pm 0.003$ & $0.032 \pm 0.007$ & $0.81 \pm 0.05$ & $0.49 \pm 0.07$ \\
\hline Temporal cortex & $0.038 \pm 0.003$ & $0.019 \pm 0.004^{\prime \prime}$ & $0.042+0.003$ & $0.036 \pm 0.008$ & $0.91 \pm 0.07$ & $0.54+0.12$ \\
\hline Thalatnus & $0.045 \pm 0.003$ & $0.022+0.005^{\prime \prime}$ & $0.048 \pm 0.003$ & $0.039 \pm 0.009^{\prime \prime}$ & $0.94+0.10$ & $0.56 \pm 0.11$ \\
\hline Caudate nucleus & $0.036 \pm 0.005$ & $0.017 \pm 0.0002^{b}$ & $0.036 \pm 0.003$ & $0.029 \pm 0.005^{\prime \prime}$ & $1.00 \pm 0.10$ & $0.61 \pm 0.12$ \\
\hline Putamen & $0.043 \pm 0.003$ & $0.019 \pm 0.004^{\prime \prime}$ & $0.042 \pm 0.005$ & $0.032 \pm 0.0077^{u}$ & $1.02+0.05$ & $0.62+0.13$ \\
\hline Cerebellar cortex & $0.047 \pm 0.003$ & $0.021+0.004^{\prime \prime}$ & $0.052 \div 0.005$ & $0.037 \pm 0.008^{\prime \prime}$ & $0.91+0.12$ & $0.58 \pm 0.12$ \\
\hline
\end{tabular}

Data are mean \pm SD values obtained from six subjects.

$" p<0.05, " p<0.0001, " p<0.005$ compared with the corresponding baseline value. 


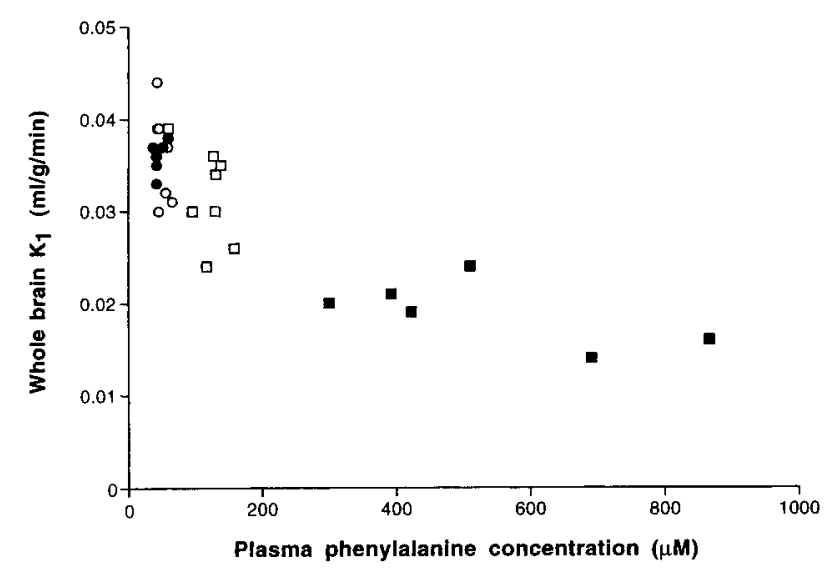

FIG. 3. Relationship between $\left[{ }^{11} \mathrm{C}\right] \mathrm{ACHC}$ influx rate constant and plasma phenylalanine concentration. Data were obtained from the six subjects reported in the present study before (-) and after (ם) oral ingestion of phenylalanine and from a previously reported study (Koeppe et al., 1991) of eight subjects before (C) and after ([.j) oral administration of aspartame. Plasma phenylalanine concentrations were determined at the end of the baseline scan just before ingestion of phenylalanine or aspartame (zero-time) and 60 min after ingestion of phenylalanine or aspartame at the time the second scan was started.

alanine in four subjects analyzed by the dual-probe system, but it decreased in only two of three patients evaluated by PET. The brain uptake rate calculated from the data obtained in normal subjects using the dual-probe system $(1.4 \mathrm{nmol} / \mathrm{g} / \mathrm{min})$ is similar to the rate of methionine transport across the $\mathrm{BBB}$ of the rat measured in the presence of normal plasma concentrations of other amino acids $(1.7 \mathrm{nmol} / \mathrm{g} / \mathrm{min}$ ) (Smith et al. 1987).

Knudsen et al. (1990) used a double indicator technique to measure the uptake and efflux of radiolabeled phenylalanine, tryptophan, leucine, tyrosine, and arginine under basal conditions. They concluded that there was marked asymmetry of transport, with amino acid transport from brain to blood occurring at a rate that was eight to 12 times greater than from blood to brain. Subsequently, they showed that the efflux rate constant but not the influx rate constant for phenylalanine was reduced in patients with hepatic encephalopathy (Knudsen et al., 1993). In contrast, we did not observe very large differences in the influx and efflux rate constants for ACHC transport under baseline conditions (Table 1). This apparent discrepancy may be explained by the proposed asymmetry of BBB amino acid transporters. For example, one model has the Asystem amino acid carrier on only the abluminal membrane and the L-system carrier on both the luminal and abluminal membranes (Betz and Goldstein, 1978, 1986). The amino acids studied by Knudsen et al. (1990) have affinity for both carriers, whereas ACHC has affinity for only the L-system (Matthews and Zand, 1977).

The kinetics of phenylalanine transport into mi- crovessels isolated from human brain were studied by Choi and Pardridge (1986). The results of competitive inhibition studies using this in vitro preparation suggested the presence of two phenylalanine transport systems: one with a $K_{\text {пा }}$ of $22 \mu M$, a value similar to that observed in the rat in vivo, and a second, very-highaffinity transport system $\left(K_{\mathrm{m}}=0.26 \mu M\right)$. However, in a later study, Hargreaves and Pardridge ( 1988 ) measured the transport of eight LNAAs into isolated brain microvessels and concluded that the high-affinity transport system was more important. $K_{\mathrm{m}}$ values varied between $0.30 \mu . M$ for phenylalanine and $8.8 \mu M$ for valine.

It is probably not possible to relate directly the results of in vitro studies using isolated cerebral capillaries with those of in vivo studies. In isolated capillaries, it is uptake across the abluminal rather than the luminal membrane that predominates, whereas transport across the luminal membrane is measured in vivo. Only the lower-affinity transporters are seen in the in vivo experiments (Smith et al., 1987). Differences in the kinetic constants measured with in vitro as compared with in vivo techniques may be related to the previously mentioned asymmetry of BBB amino acid transporters (Betz and Goldstein, 1978; Goldstein and Betz, 1986; Smith, 1991). Thus, it is unlikely that the differences between the in vivo rat experiments and the in vitro experiments with human microvessels are due to a species difference.

The results obtained in vivo are consistent with the presence of the lower-affinity transporter of the two that have been described in isolated brain capillaries, but the affinity of this transporter is believed to be quite high in comparison with the LNAA transporter in other tissues (Pardridge, 1986; Smith, 1991). Our studies support this idea, because the scalp did not exhibit the same competitive inhibition of ACHC uptake as did the brain.

In summary, the value for $K_{\mathrm{i}}^{\text {Phc }}$ that was calculated in the present study supports the proposal that there is a substantial degree of saturation of the LNAA transporter at the human $\mathrm{BBB}$. Thus, in the presence of

TABLE 2. Kinetic parameters for inhibition of $A C H C$ transport by phenylalanine

\begin{tabular}{|c|c|c|}
\hline & \multicolumn{2}{|c|}{ Using inhibition constants for } \\
\hline & $\begin{array}{l}\text { Rat brain } \\
\text { in vivo" }\end{array}$ & $\begin{array}{l}\text { Human brain } \\
\text { microvessels in vitro" }\end{array}$ \\
\hline$K_{\mathrm{i}}^{\mathrm{Phc}}(\mu M)$ & 13.2 & 1.00 \\
\hline$V_{\max } / K_{\mathrm{m}}$ for $\mathrm{ACHC}(\mathrm{ml} / \mathrm{g} /$ & 0.302 & 3.73 \\
\hline$K_{\mathrm{d}}^{\mathrm{AC}}(\mathrm{HC}(\mathrm{ml} / \mathrm{g} / \mathrm{min})$ & 0.0119 & 0.0129 \\
\hline
\end{tabular}

Variability of all values is $<10 \%$ as judged by analysis of the covariance matrices.

"Smith et al. (1987).

"Hargreaves and Pardridge (1988). 
rather large and persistent increases in plasma amino acid concentrations, as occurs in certain human metabolic diseases, LNAA uptake by brain might indeed be reduced sufficiently to compromise the synthesis of proteins and neurotransmitters.

Acknowledgment: This work was supported by grant P0I-NS15655 from the National Institutes of Health. We are grateful to Dr. M. Hariharan for performing plasma amino acid analyses. The authors would like to thank the Nuclear Medicine PET staff for production of the radiopharmaceutical and for acquisition of the PET data reported in this work.

\section{REFERENCES}

Alpert N. M., Eriksson L., Chang J. Y., Bergstrom M., Litton J. E., Correia J. A., Bohm C., Ackerman R. H., and Taveras J. M. (1984) Strategy for the measurement of regional cerebral blood flow using short-lived tracers and emission tomography. $J$. Cereb. Blood Flow Metab. 4, 28-34.

Aoyagi M., Agranoff B. W., Washburn L. C., and Smith Q. R. (1988) Blood-brain barrier transport of 1-aminocyclohexanecarboxylic acid, a nonmetabolizable amino acid for in vivo studies of brain transport. $J$. Neurochem. 50, 1220-1226.

Bergström M., Ericson K., Hagenfeldt L., Mosskin M., von Holst H., Norén G., Eriksson L., Ehrin E., and Johnström P. (1987) PET study of methionine accumulation in glioma and norma brain tissue: competition with branched chain amino acids. $J$. Comput. Assist. Tomogr. 11, 208-213.

Bewz A. L. and Goldstein G. W. (1978) Polarity of the bloodbrain barrier: neutral amino acid transport into isolated brain capillaries. Science 202, 225-227.

Betz A. L. and Goldstein G. W. ( 1986 ) Specialized properties and solute transport in brain capillaries. Annu. Rev. Physiol. 48, $241-250$.

Carter J. H., Nutt J. G., Woodward W. R., Hatcher L. F., and Trotman T. L. (1989) Amount and distribution of dietary protein affects clinical response to levodopa in Parkinson's disease. Neurology 39, $552-556$.

Choi T. B. and Pardridge W. M. (1986) Phenylalanine transport at the human blood-brain barrier. J. Biol. Chem. 261, 65366541 .

Daniel P. M., Moorhouse S. R., and Pratt O. E. (1976) Do changes in blood levels of other aromatic amino acids influence levodopa therapy? Lancet $1,95$.

Fenstermacher J. D., Blasberg R. G., and Patlak C. S. (1981) Methods for quantifying the transport of drugs across brain barrier systems. Pharmacol. Ther. 14, 217-248.

Goldstein G. W. and Betz A. L. ( 1986) The blood-brain barrier. Sci. Am. 254, 74-83.

Hargreaves K. M. and Pardridge W. M. (1988) Neutral amino acid transport at the human blood-brain barrier. J. Biol. Chem. 263, $19392-19397$

Hariharan M., Naga S., and VanNoord T. (1993) Systematic approach to the development of plasma amino acid analysis by high-performance liquid chromatography with ultraviolet detection with precolumn derivatization using phenyl isothiocyanate. J. Chromatogr. 621, 15-22.

Hayes R. L., Washburn L. C., Wieland B. W., Sun T. T., Anon
J. B., Butler T. A., and Callahan A. P. (1978) Synthesis and purification of ${ }^{11} \mathrm{C}$-carboxyl-labeled amino acids. Int. J. Appl. Radiat. Isot. 29, 186-187.

Kaufman S. (1977) Phenylketonuria: biochemical mechanisms, in Advances in Neurochemistry, Vol. 2 (Agranoff B. W. and Aprison M. H., eds), pp. 1-133. Plenum Press, New York.

Knudsen G. M., Pettigrew K. D., Patlak C. S., Hertz M. M., and Paulson O. B. (1990) Asymmetrical transport of amino acids across the blood-brain barrier in humans. J. Cereb. Blood Flow Metab. 10, 698-706.

Knudsen G. M., Schmidt J., Almdal T., Paulson O. B., and Vilstrup H. ( 1993 ) Passage of amino acids and glucose across the bloodbrain barrier in patients with hepatic encephalopathy. Hepatology 17, $987-992$.

Koeppe R. A., Mangner T., Betz A. L., Shulkin B. L., Allen R., Kollros P., Kuhl D. E., and Agranoff B. W. (1990) Use of $\left[{ }^{1 '} \mathrm{C}\right.$ ] aminocyclohexanecarboxylate for the measurement of amino acid uptake and distribution volume in human brain. $J$. Cereb. Blood Flow Metab. 10, 727-739.

Koeppe R. A., Shulkin B. L., Rosenspire K. C., Shaw L. A., Betz A. L., Mangner T., Price J. C., and Agranoff B. W. (1991) Effect of aspartame derived phenylalanine on neutral amino acid uptake in human brain: a positron emission tomography study. J. Neurochem. 56, 1526-1535.

Leenders K. L., Poene W. H., Palmer A. J., Brenton D. P., and Frackowiak R. (1986) Inhibition of L-[18-F]-fluorodopa uptake into human brain by amino acids demonstrated by positron emission tomography. Ann. Neurol. 20, 258-261.

Matthews R. H. and Zand R. (1977) Basis for substrate preference of amino acid transport system $L$ over amino acid transport system A. Biochemistry 16, 3820-3824.

Momma S., Aoyagi M., Rapoport S. I., and Smith Q. R. (1987) Phenylalanine transport across the blood-brain barrier as studied with the in situ brain perfusion technique. J. Neurochem. 48, $1291-1300$.

Oldendorf W. H., Sisson W. B., and Silverstein A. (1971) Brain uptake of selenomethionine SE 75: Il. Reduced brain uptake of selenomethionine SE 75 in phenylketonuria. Arch. Neurol. 24, 524-528.

O'Tuama L. A., Guilarte T. R., Douglass K. H., Wagner H. N., Wong D. F., Dannals R. F., Ravert H. T., Wilson A. A., LaFrance N. D., Bice A. N., and Links J. M. (1988) Assessment of [ " C lL-methionine transport into the human brain. J. Cereb. Blood Flow Metab. 8, 341-345.

Pardridge W. M. ( 1977) Kinetics of competitive inhibition of neutral amino acid transport across the blood-brain barrier. J. Neurochem. 28, 103-108.

Pardridge W. M. (1983) Brain metabolism: a perspective from the blood-brain barrier. Physiol. Rev. 63, 1481-1535.

Pardridge W. M. (1986) Potential effects of the dipeptide sweetener aspartame on the brain, in Nutrition and the Brain (Wurtman R. J. and Wurtman J. J., eds), pp. 199--241. Raven Press, New York.

Smith Q. R. (1991) The blood-brain barrier and the regulation of amino acid uptake and availability to brain. Adv. Exp. Med. Biol. 291, 55-71.

Smith Q. R., Takasato Y., Sweeney D. J., and Rapoport S. I. (1985) Regional cerebrovascular transport of leucine as measured by the in situ brain perfusion technique. J. Cereb. Blood Flow Metab. 5, 300-311.

Smith Q. R., Momma S., Aoyagi M., and Rapoport S. I. (1987) Kinetics of neutral amino acid transport across the blood-brain barrier. J. Neurochem. 49, 1651-1658. 